\title{
Safety and Efficacy of Auto-lipofilling in Facial Rejuvenation: a meta-analysis study
}

\author{
Abdalla Salah Abdalla Elsadany, ${ }^{1}$ M.B.B.Ch, Yasser Helmy Ali, ${ }^{1}$ MD, Mostafa Mohamed Ellaban, ${ }^{1}$ MD.
}

\section{* Corresponding Author:}

Abdalla Salah Abdalla Elsadany abdallaelsadany@azhar.edu.eg

Received for publication July 9, 2021; Accepted August 21, 2021; Published online January 21, 2022.

\section{Copyright The Authors published by Al-Azhar University, Faculty of Medicine, Cairo, Egypt. Users have the right to read, download, copy, distribute, print, search, or link to the full texts of articles under the following conditions: Creative Commons Attribution- Share Alike 4.0 International Public License (CC BY-SA 4.0).}

doi: 10.21608/aimj.2021.82971.1523.

${ }^{I}$ Plastic Surgery Department, Faculty of Medicine, Al-Azhar University, Cairo, Egypt.

\begin{abstract}
Background: : Autologous fat transfer has been practiced and described as a promising method in facial rejuvenation. Many randomized and observational studies have been published with scanty of evidence came from review and meta-analysis.

Aim of the study: to evaluate the evidence-based practice regarding the safety of autologous fat transfer in an updated meta-analysis study.

Patients and Methods: Systemic review and meta-analysis using (PRI SMA) statement were achieved. Literature search was performed in PubMed, PLOS and Cochrane library. Many of the search engines have been used including EKB platform to download the articles from SCOPUS and Clarivate databases, starting from 2017 to 2021.

Results: Out of 132 articles only 6 articles were included in this study. Study included 255patients in total with an average follow-up only for 12 months. Total sessions for all patients in all studies were once for every patient. Analysis showed complication rate about $5 \%$. Three studies reported overall surgeon satisfaction and patient satisfaction were $89 \%$, $81 \%$ respectively.

Conclusion: Although this updated meta-analysis in the period from 2017 to 2021 but, the evidence of autologous fat transfer safety, still limited to have an evidence-based practice. Well-designed multicentric randomized clinical trials and big series cohort studies are strongly recommended to properly conclude about the safety.
\end{abstract}

Keywords: auto-lipofilling; fat injection; facial rejuvenation
Disclosure: The authors have no financial interest to declare in relation to the content of this article. The Article Processing Charge was paid for by the authors.

Authorship: All authors have a substantial contribution to the article.

\section{INTRODUCTION}

Over more than two decades Lipo-filling has been emergent and described as a promising technique in volume restoration in different areas in the body and for facial rejuvenation. However, huge number of articles have been published, and describes different techniques in fat harvestings, processing and injection, there is no evidence-based practice regarding the safety and the standardization of best fitting lipo-filling technique in the face ${ }^{1,10}$. Previous study conducted by Jan W. et al, ${ }^{11}$ published in PRS global open in 2017 , concluded that autologous fat transfer (AFT) appears to be a hopeful method in facial rejuvenation, however their study showed deficiency and limitation of evidence due to heterogenicity, lack of proper reporting of fat necrosis and satety. Based on this previous systematic review and meta-analysis, this study purposes to assess the evidence-based practice concerning the safety of autologous fat transfer in an updated meta-analysis study on articles published in the period from 2017-2021.

\section{MATERIALS AND METHODS}

\section{METHODOLOGY}

Systemic review and meta-analysis by using the preferred reporting items for systemic review and meta-analysis (PRISMA) . ${ }^{12}$ statement was achieved. Literature search was performed in PubMed, PLOS and Cochrane library. Many of the search engines have been used including Egyptian Knowledge Bank (EKB) platform to download the articles from Scopus and Clarivate databases.

The study retrieved the Data of articles published starting from 2017 to 2021. All published articles studying the safety of autologous fat transfer in facial rejuvenation surgery were included in the study.

The search terms and their synonymous and closely relevant words were used in this study including (auto-lipofilling, auto-fat transfer, facial rejuvenation, safety, volumetric assessment of fat, complication of lipofilling, traumatic fat necrosis and satisfaction with fat injection). 


\section{RESULTS}

\section{Eligibility Criteria:}

The included studies were original randomized controlled trials and cohort studies done on facial rejuvenation with the use of AFT with or without additives,

Study excluded articles that reported on other surgical procedures or injectables even if reporting fat grafting with or pre the surgical procedure. However, articles merging laser-resurfacing with AFT procedures or studies that involved mixtures of treatment (i.e., AFT + surgical procedures) but visibly described on AFT- related complications were involved. We excluded duplicate studies, case reports, or case series with a sample size $<10$ and articles with an average follow-up time $<6$ months.

\section{Study Selection}

Studies were primary included or excluded by title and abstract. Titles were recorded using Endnote by Clarivate and Mendeley by Scopus. Two independent surgeons did data extraction systematically, adhering to the preferred reporting items for systemic review and meta-analysis (PRISMA) guidelines. Summary measures was assembled in a random-effects model meta-analysis. Study assessed type of graft harvesting (nano-micro compositional or structured), processing, number of autologous fat transfer sessions, graft survival, the incidence of autologous fat transfer related complications especially fat necrosis or fat embolism and the patient and surgeon satisfaction.

\section{Inclusion criteria}

All randomized control study and observational studies either cohort study or retro-analysis which are discussing the auto fat transfer in facial rejuvenation were included in this study. The techniques for fat harvesting, processing, injection, safety and outcome satisfaction and complication where focused on and analyzed in this study.
$\mathrm{T}$ The data bases search resulted in a total of 132 article. Sixty-nine articles were excluded as they were duplicated. Inspection of the title and abstract lead to the exclusion of 49 studies as they are irrelevant. The remaining 14 clinical trials were selected for full-text screening. After full text screening 6 papers were involved in this systemic review and meta-analysis (table 1 )

Reasons for exclusion of the 8 studies were that they were Case report, review studies, case-series and if fat grating was for reconstructive purpose.

\section{Complication}

The reported complications (Table 1) among the included studies were rare and with minimal effect. The mentioned complications were observed immediately after operation and included erythema in injected site, edema, bruising and ecchymosis. Their management was conservative and did not necessitate any clinical action.

Complications such as infections, irregularities, asymmetry, overcorrections, chronic edema and donor site hematoma were not reported in included studies.

Charles-de-Sa et al. reported that; only local transient effects were sometimes noticed immediately after fat injection, These effects did not necessitate any clinical action. Gontijo-de-Amorim et al., temporary events, were reported such as edema and ecchymosis. $\mathrm{Hu} \&$ Xue et al. He reported obvious oedema for 2 weeks after the lipofilling procedure. Luo \& Zhang et al. Less noticeable fibrotic nodes occurred on 14 sides in 20 days, but these patients slowly recovered over the 3 to 6 months. Willemsen et al. reported no complication occurred during the study, while Yin \& $\mathrm{Li}$, et al minimized the complication issue in their report. 


\begin{tabular}{|c|c|c|}
\hline Article title & Complication & Management \\
\hline $\begin{array}{l}\text { Photoaged Skin Therapy with } \\
\text { Adipose-derived Stem Cells }\end{array}$ & $\begin{array}{l}\text { Local transitory effects were occasionally observed } \\
\text { immediately after the cell injection, such as } \\
\text { injection-site erythema, edema, bruising or } \\
\text { induration No later skin reactions were Observed }\end{array}$ & $\begin{array}{l}\text { These effects did not require any } \\
\text { clinical treatment, and the patients } \\
\text { returned to the normal skin condition } \\
\text { within less than } 48 \text { hours }\end{array}$ \\
\hline $\begin{array}{l}\text { Mechanical Supplementation With } \\
\text { the } \\
\text { Stromal Vascular Fraction Yields } \\
\text { Improved Volume Retention in Facial } \\
\text { Lipotransfer: A 1-Year Comparative } \\
\text { Study }\end{array}$ & $\begin{array}{l}\text { No severe complications, such as infections, septic } \\
\text { shock, cellulitis, fat embolism, or anemia, were } \\
\text { recorded. Patients in both groups experienced only } \\
\text { transitory events, such as ecchymosis and edema, } \\
\text { which are common results of fat grafting in the early } \\
\text { postoperative period. }\end{array}$ & Conservative \\
\hline $\begin{array}{l}\text { Comparative study of autologous fat } \\
\text { vs hyaluronic acid in correction of the } \\
\text { nasolabial folds }\end{array}$ & $\begin{array}{l}\text { In the early stage, Edema usually was evident for } 2 \\
\text { weeks after the procedure. Bleeding complications } \\
\text { usually were limited to transient mild ecchymoses } \\
\text { that usually rapidly resorbed. Embolization and } \\
\text { arterial occlusion were not found. }\end{array}$ & $\begin{array}{l}\text { Theoretically, the most severe risk } \\
\text { could } \\
\text { be minimized by using a low- } \\
\text { pressure, blunt cannula, and the } \\
\text { withdrawal injection technique. }\end{array}$ \\
\hline $\begin{array}{l}\text { Correction of the Tear Trough } \\
\text { Deformity and Concomitant } \\
\text { Infraorbital Hollows With } \\
\text { extracellular Matrix/Stromal } \\
\text { Vascular Fraction Gel }\end{array}$ & $\begin{array}{l}\text { Nonobvious fibrotic nodules occurred on } 14(21.2 \%) \\
\text { sides within } 20 \text { days, with all of these patients } \\
\text { gradually recovering over the next } 3 \text { to } 6 \text { months. No } \\
\text { obvious swelling was observed, consistent with } \\
\text { previous findings }\end{array}$ & \\
\hline $\begin{array}{l}\text { The addition of PRP to facial } \\
\text { lipofilling: double blind placebo- } \\
\text { controlled randomized trial. }\end{array}$ & No complications occurred during the study. & NR \\
\hline $\begin{array}{l}\text { Autologous fat graft assisted by } \\
\text { stromal vascular fraction improves } \\
\text { facial skin quality: a randomized } \\
\text { controlled trial }\end{array}$ & $\begin{array}{l}\text { satisfactory clinical results were generally achieved } \\
\text { without any major complications. }\end{array}$ & \\
\hline
\end{tabular}

\section{DISCUSSION}

This study was done to achieve a broad overview of the accessible evidence on the consequences of AFT in facial rejuvenation along with independent result measures and a clear explanation of the utilized techniques. Concern is the little number of research that assess AFT in rejuvenation of the face in this survey $1^{3-18}$

In this study most articles described, to various degree, the methods of harvesting and preparing the fat grafting

The reported complications among the included studies were rare and with minimal effect and there management were conservative and did not require any clinical treatment.

Although AFT has several clear benefits over other cutaneous fillings in conditions of biocompatibility, such as the non-appearance of hypersensitivity responses and the dangers of granuloma creation, other problems such as fat necrosis have to be taken into account.

\section{CONCLUSION}

The published data are still lacking to have a conclusive and strong evidence regards the safety of auto lipofilling in facial rejuvenation, in terms of safety and complication.

\section{REFERENCES}

1. Suh, A., et al., Adipose-derived cellular and cellderived regenerative therapies in dermatology and aesthetic rejuvenation. Ageing Res Rev, 2019. 54: p. 100933.

2. Tonnard, P.L., et al., Aging of the Upper Lip: Part II. Evidence-Based Rejuvenation of the Upper Lip-A Review of 500 Consecutive Cases. Plast Reconstr Surg, 2019. 143(5): p. 1333-42.

3. Kakagia, D. and N. Pallua, Autologous Fat Grafting:In Search of the Optimal Technique. 2014. 21(3): p. 327-36.

4. Clauser, L., et al., Autologous Fat Transfer for Facial Augmentation: Surgery and Regeneration. $J$ Craniofac Surg, 2019. 30(3): p. 682-5.

5. Bi, H.-S., et al., Basic and Clinical Evidence of an Alternative Method to Produce Vivo Nanofat. 2018. 131(5): p. 588-93. 
6. Mulya, A. and J.P. Kirwan, Brown and Beige Adipose Tissue: Therapy for Obesity and Its Comorbidities? Endocrinol Metab Clin North Am, 2016. 45(3): p. 605-21.

7. Le, T.P., et al., Effect of autologous fat injection on lower eyelid position. Ophthalmic Plast Reconstr Surg, 2014. 30(6): p. 504-7.

8. Ferraro, G.A., et al., Effects of a new centrifugation method on adipose cell viability for autologous fat grafting. Aesthetic Plast Surg, 2011. 35(3): p. 341-8.

9. van Dongen, J.A., et al., The Effects of Facial Lipografting on Skin Quality: A Systematic Review. Plast Reconstr Surg, 2019. 144(5): p. 784e-97e.

10. Piasecki, J.H., et al., An experimental model for improving fat graft viability and purity. 2007. 119(5): p. 1571-83.

11. Groen, J.W., et al., Autologous Fat Transfer for Facial Rejuvenation: A Systematic Review on Technique, Efficacy, and Satisfaction. Plast Reconstr Surg Glob Open, 2017. 5(12): p. e1606.

12. Moher, D., et al., Preferred reporting items for systematic reviews and meta-analyses: the PRISMA statement. J Clin Epidemiol, 2009. 62(10): p. 100612. 